\title{
Blood Pressure Monitoring
}

2.8 In Patients with Isolated Ambulatory Hypertension Central Blood Pressure and Augmentation Index are Increased: the VOBARNO Study

A. Paini (1), ML. Muiesan (1), M. Salvetti (1), E. Belotti (1), G. Gallbassini (1),

C. Agabiti-Rosei (1), C. Aggiusti (1), L. Micheletti (1), F. Marino (1), F. Bertacchini

(1), E. Agabiti-Rosei (1)

(1)Università di Brescia, Brescia, Italy

Introduction. Different blood pressure (BP) patterns have been identified by the use of both office and 24 hours BP measurement: sustained normotension (NT), isolated office hypertension (IOH), isolated ambulatory hypertension (IAH) and hypertension (HT). Pulse-wave analysis (PWA) has been proposed for non-invasive evaluation of central BP; furthermore, the derived 'augmentation index' (AIx) is an accepted indirect index of arterial stiffness.

Aim. To assess the relationships between PWA measures and BP patterns in a general population sample in Northern Italy.

Methods. In 242 untreated subjects (age 54.0 \pm 8.6 years, BMI $25.3 \pm 4.0,47 \%$ males) radial artery applanation tonometry and PWA were used to derive central aortic pressures and AIx. All subjects underwent laboratory examinations and both clinic and $24 \mathrm{~h} \mathrm{BP}$ measurement. Subjects were divided into subgroups: NT (office BP $<140 / 90$ and 24-hour $\mathrm{BP}<125 / 80 \mathrm{mmHg}$ ), IOH (office BP $>140 / 90$ and 24-hour $\mathrm{BP}<125 / 80 \mathrm{mmHg}$ ), IAH (office $\mathrm{BP}<140 / 90$ and 24-hour $\mathrm{BP}>125 / 80 \mathrm{mmHg}$ ) and HT(office $\mathrm{BP}>140 / 90$ and 24-hour $\mathrm{BP}>125 / 80 \mathrm{mmHg}$ ).

Results. Patients with IAH and HT were older than NT(59.5 \pm 8.4 and $55.3 \pm 9.3$ vs $51.1 \pm 6.4$ years, respectively, $\mathrm{p}<0.01)$. BMI was higher in $\mathrm{IOH}$ and $\mathrm{HT}$ than in NT(25.5 \pm 3.9 and $26.8 \pm 4.3 \mathrm{vs} 23.7 \pm 3.3$, respectively, $\mathrm{p}<0.01$ ). After adjusting for confounding variables (including also mean $\mathrm{BP}$ and $\mathrm{HR}$ ) $\mathrm{AIx}$ was significantly higher in IOH, IAH and HT in comparison to NT $(31.1 \pm 1.0,30.8 \pm 1.8,31.3 \pm 1.0 \mathrm{vs}$ $26.6 \pm 1.0$, respectively, $\mathrm{p}<0.01$ ). Central SBP was significantly higher in $\mathrm{HT}$, but also in IOH and IAH, than in NT (HT 120.3 \pm 0.7 , IOH120.6 \pm 0.7 , IAH $121.0 \pm 1.2$ vs NT $117.8 \pm 0.7 \mathrm{mmHg}, \mathrm{p}<0.01$ ).

Conclusions. In a general population sample central SBP and AIx are greater in patients with sustained, office or ambulatory hypertension in respect to subject with clinic and 24 hours normal BP values. Particularly in IAH, despite normal brachial BP values, central BP is significantly increased, possibly contributing to increase cardiovascular risk. 